\title{
Inferior Parathyroid Gland
}

National Cancer Institute

\section{Source}

National Cancer Institute. Inferior Parathyroid Gland. NCI Thesaurus. Code C32787.

Either of two paired parathyroid glands distal to the head. 